\title{
Atomic Layer Deposition of Lanthanum-Based Ternary Oxides
}

\section{Citation}

Wang, Hongtao, Jun-Jieh Wang, Roy Gerald Gordon, Jean-Sébastien M. Lehn, Huazhi Li, Daewon Hong, and Deo V. Shenai. 2009. Atomic layer deposition of lanthanum-based ternary oxides. Electrochemical and Solid-State Letters 12(4): G13-G15.

\section{Published Version}

doi:10.1149/1.3074314

\section{Permanent link}

http://nrs.harvard.edu/urn-3:HUL.InstRepos:9310888

\section{Terms of Use}

This article was downloaded from Harvard University's DASH repository, and is made available under the terms and conditions applicable to Other Posted Material, as set forth at http:// nrs.harvard.edu/urn-3:HUL.InstRepos:dash.current.terms-of-use\#LAA

\section{Share Your Story}

The Harvard community has made this article openly available.

Please share how this access benefits you. Submit a story.

\section{Accessibility}




\title{
Atomic Layer Deposition of Lanthanum-Based Ternary Oxides
}

\author{
Hongtao Wang, ${ }^{a}$ Jun-Jieh Wang, ${ }^{\text {b }}$ Roy Gordon, ${ }^{b, *, z}$ Jean-Sébastien M. Lehn, ${ }^{c}$ \\ Huazhi Li, ${ }^{c}$ Daewon Hong, ${ }^{c}$ and Deo V. Shenai ${ }^{c}$ \\ ${ }^{a}$ School of Applied Science and Engineering and ${ }^{b}$ Department of Chemistry and Chemical Biology, \\ Harvard University, Cambridge, Massachusetts 02138, USA \\ ${ }^{c}$ Rohm and Haas Electronic Materials, North Andover, Massachusetts 01845, USA
}

Lanthanum-based ternary oxide $\mathrm{La}_{x} \mathrm{M}_{2-x} \mathrm{O}_{3}(\mathrm{M}=\mathrm{Sc}$, Lu, or Y) films were deposited on HF-last Si substrates by atomic layer deposition. Both $\mathrm{LaScO}_{3}$ and $\mathrm{LaLuO}_{3}$ films are amorphous while the as-deposited $\mathrm{La}_{x} \mathrm{Y}_{2-x} \mathrm{O}_{3}$ films form a polycrystalline layer/ amorphous layer structure on Si. Transmission electron microscopy and electrical analysis show the absence of interfacial layers. The dielectric constants for $\mathrm{LaScO}_{3}, \mathrm{LaLuO}_{3}$, and $\mathrm{La}_{1.23} \mathrm{Y}_{0.77} \mathrm{O}_{3}$ films are $\sim 23,28 \pm 1$, and $17 \pm 1.3$, respectively, with leakage current density up to 6 orders of magnitude lower than that of thermal $\mathrm{SiO}_{2}$ with the same effective oxide thickness. Conformal coating thickness is demonstrated on holes with aspect ratio $\sim 80: 1$.

(C) 2009 The Electrochemical Society. [DOI: 10.1149/1.3074314] All rights reserved.

Manuscript submitted November 30, 2008; revised manuscript received January 5, 2009. Published January 29, 2009.

Hafnium oxide has been widely studied as an alternative gate dielectric to replace silicon dioxide for metal-oxide-semiconductor field-effect transistors (MOSFETs) and dynamic random access memories. In 2007, Intel Corporation announced its accomplishment of integrating $\mathrm{HfO}_{2}$ into MOSFETs with the physical gate length of $45 \mathrm{~nm} .{ }^{1}$ However, pure $\mathrm{HfO}_{2}$ is readily crystallized at temperatures as low as $\sim 500^{\circ} \mathrm{C}^{2}$ Amorphous dielectrics with high thermal stability are still preferred because they have no intrinsic defects, such as grain boundaries, and show homogeneous electrical properties, provided they still have the advantages of $\mathrm{HfO}_{2}$, such as high dielectric constant $(\kappa \sim 22$ to 23$)$, wide bandgap $\left(E_{\mathrm{g}}=5.5 \mathrm{eV}\right)$, and low leakage. ${ }^{3}$ Recent reports show that lanthanum-based ternary oxides, such as lanthanum scandate $\left(\mathrm{LaScO}_{3}\right)$ and lanthanum lutetium oxide $\left(\mathrm{LaLuO}_{3}\right)$, can meet all these requirements. These materials were grown by molecular beam deposition, ${ }^{4}$ pulsed laser deposition, ${ }^{5}$ or atomic layer deposition (ALD). ${ }^{6}$ However, these lanthanide oxide films had nanometer-thick interfacial layers when deposited on Si substrates, which made it impossible to scale the effective oxide thickness (EOT) to the subnanometer range. Previously, we found that interfacial layers could be avoided when ternary rare earth oxide $\left(\mathrm{GdScO}_{3}\right)$ films were deposited on $\mathrm{Si}$ by ALD from metal amidinate precursors and $\mathrm{H}_{2} \mathrm{O}$. This research shows that ALD-deposited $\mathrm{LaScO}_{3}$ and $\mathrm{LaLuO}_{3}$ thin films have desirable structural and electrical properties, and are free of interfacial layers. Lanthanum yttrium oxide thin films were also deposited by ALD under the similar condition, in order to show the importance of the choice of the element combination.

Here we report ALD of $\mathrm{LaScO}_{3}$ and $\mathrm{LaLuO}_{3}$ thin films that are free of interfacial layers, while retaining the desirable high-к and amorphous properties. Thus, we obtained films with EOT values $<1 \mathrm{~nm}$ and very low leakage. Polycrystalline lanthanum yttrium oxide thin films were also deposited by ALD under similar conditions, showing the importance of the proper choice of element combinations.

\section{Experimental}

The oxide films were deposited in a flow-type ALD reactor with water vapor alternating with vapors of metal amidinate precursors: lanthanum tris $\left(N, N^{\prime}\right.$-di-iso-propylformamidinate), scandium $\operatorname{tris}\left(N, N^{\prime}\right.$-diethylacetamidinate), lutetium $\operatorname{tris}\left(N, N^{\prime}\right.$-diethylformamidinate $)$, and yttrium tris $\left(N, N^{\prime}\right.$-di-iso-propylacetamidinate). The ternary oxide films $\mathrm{La}_{x} \mathrm{M}_{2-x} \mathrm{O}_{3}(\mathrm{M}=\mathrm{Sc}, \mathrm{Lu}$, or $\mathrm{Y})$ were deposited by repeatedly growing $m$-layers of $\mathrm{La}_{2} \mathrm{O}_{3}$ followed by $n$-layers of $\mathrm{M}_{2} \mathrm{O}_{3}$ with $m, n=1$ or 2 . The deposition temperature was $300^{\circ} \mathrm{C}$ for $\mathrm{LaScO}_{3}$ and $\mathrm{LaLuO}_{3}$, and $280^{\circ} \mathrm{C}$ for $\mathrm{La}_{x} \mathrm{Y}_{2-x} \mathrm{O}_{3}$. n-Type $\mathrm{Si}(100)$,

\footnotetext{
* Electrochemical Society Active Member

${ }^{\mathrm{z}}$ E-mail: gordon@chemistry.harvard.edu
}

with resistivity $0.5-1 \Omega \mathrm{cm}$, was selected as the substrate. All substrates were treated in UV/ozone to remove surface organic contamination, then dipped into $10 \%$ aqueous HF solution for $5 \mathrm{~s}$ and rinsed with deionized water right before deposition. Metal-oxidesemiconductor (MOS) capacitors were made to measure the electrical properties. Tungsten nitride (WN) was deposited in the same ALD reactor as a top metal electrode. ${ }^{8}$ Platinum dots were finally deposited by evaporation and liftoff and used as hard masks during the removal of exposed $\mathrm{WN}$ by reactive ion etching $\left(\mathrm{CF}_{4}+\mathrm{Ar}\right)$.

\section{Results and Discussion}

The film thickness and the number of ALD cycles have a linear relation with zero intercept (Fig. 1a), showing that growth begins immediately on H-terminated Si surfaces. For $m, n=1$ or 2 , the ternary oxide growth rate is approximately the summation of $m$ times of the growth rate of $\mathrm{La}_{2} \mathrm{O}_{3}(1.3 \AA /$ cycle $)$ and $n$ times of the growth rate of $\mathrm{M}_{2} \mathrm{O}_{3}\left(1.1 \AA /\right.$ cycle for $\mathrm{Sc}_{2} \mathrm{O}_{3}, 1.2 \AA /$ cycle for $\mathrm{Lu}_{2} \mathrm{O}_{3}$, and $0.8 \AA /$ cycle for $\mathrm{Y}_{2} \mathrm{O}_{3}$ ). The impurity contents, including carbon and nitrogen, are below the detection limit $(\sim 1 \%)$ of $\mathrm{X}$-ray photoelectron spectroscopy (XPS) (Fig. 1b). The film composition by Rutherford backscattering (not shown) depends on both the ratio $m / n$ and the metal precursors. For $m=n=1$, the ternary oxide films were determined to be $\mathrm{LaSc}_{1.02 \pm 0.07} \mathrm{O}_{3}, \mathrm{LaLu}_{1.00 \pm 0.05} \mathrm{O}_{3}$, and $\mathrm{La}_{1.23} \mathrm{Y}_{0.77} \mathrm{O}_{3}$, respectively. The compositions of $\mathrm{La}_{x} \mathrm{Y}_{2-x} \mathrm{O}_{3}$ films for various $m$ and $n$ show a linear relationship between $x / 2$ and $m /(m+0.63 n)$ with unit slope, which implies that the growth rate for each material is independent of the composition of the substrate that it is growing on. On the basis of this observation, $\mathrm{LaYO}_{3}$ films can be obtained by setting $m=2$ and $n=3$.

Figure 2a shows a sharp interface between amorphous $\mathrm{LaScO}_{3}$ and crystalline $\mathrm{Si}$ in a stack of $\mathrm{WN} / \mathrm{LaScO}_{3} / \mathrm{Si}$. Similar results were found for $\mathrm{LaLuO}_{3}$ and $\mathrm{La}_{x} \mathrm{Y}_{2-x} \mathrm{O}_{3}$ films [Cross-sectional transmission electron microscope (XTEM) images not shown]. The step coverage is close to $100 \%$ in holes with an aspect ratio of $\sim 80: 1$. Figure $2 \mathrm{~b}$ shows that a $12 \mathrm{~nm} \mathrm{LaLuO}$ film has a uniform thickness from the top to the bottom of the hole. Despite the fact that all the as-deposited binary oxides $\left(\mathrm{M}_{2} \mathrm{O}_{3}\right)$ are polycrystalline bodycentered-cubic phases determined by electron diffraction, both $\mathrm{LaScO}_{3}$ and $\mathrm{LaLuO}_{3}$ films are amorphous and homogeneous. In contrast, as-deposited $\mathrm{La}_{x} \mathrm{Y}_{2-x} \mathrm{O}_{3}$ films show a polycrystalline layer over an amorphous layer on Si by XTEM. The lattice incompatibility between these oxides and $\mathrm{Si}$ increases the activation energy barrier for nucleating crystalline phases adjacent to $\mathrm{Si}$, resulting in an amorphous lower layer of $\mathrm{La}_{x} \mathrm{Y}_{2-x} \mathrm{O}_{3}$. After the growth of a thin amorphous layer (3-7 nm), the mismatch is relaxed so that a polycrystalline layer of $\mathrm{La}_{x} \mathrm{Y}_{2-x} \mathrm{O}_{3}$ can grow on the top.

MOS capacitors were made to measure the electrical properties. Figure $3 \mathrm{a}$ shows the high-frequency $(1 \mathrm{MHz})$ capacitance-voltage (C-V) curves of $\mathrm{LaLuO}_{3}, \mathrm{LaScO}_{3}$, and $\mathrm{La}_{1.23} \mathrm{Y}_{0.77} \mathrm{O}_{3}$ films with no 


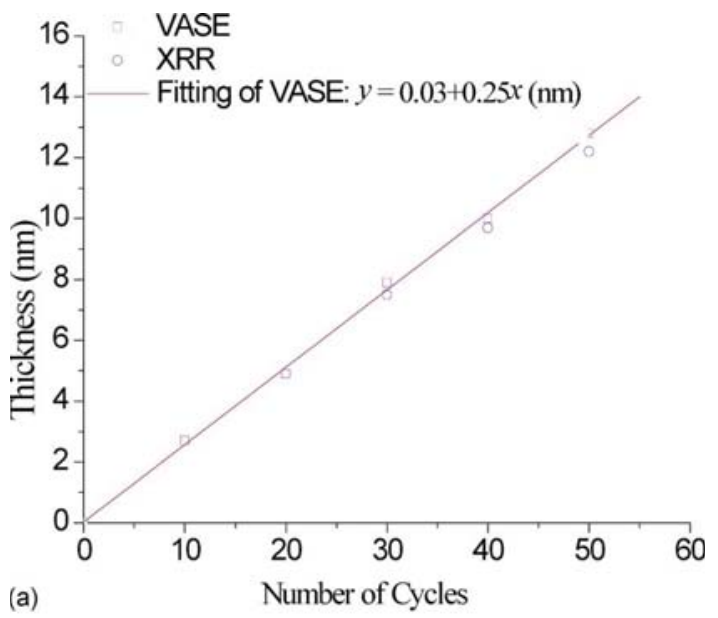

(a)

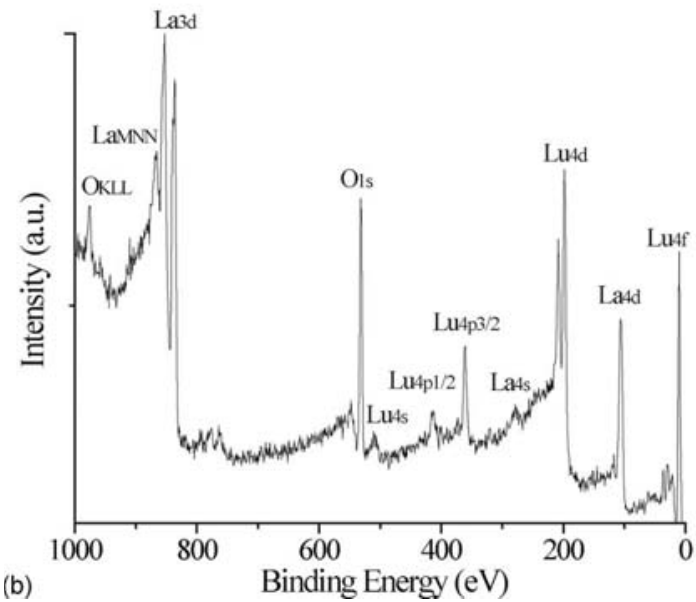

Figure 1. (Color online) (a) The thickness vs ALD cycle plot. The thickness was measured by both X-ray reflectivity (XRR) and variable angle scanning ellipsometer (VASE). (b) The XPS spectrum for $\mathrm{LaLuO}_{3}$.
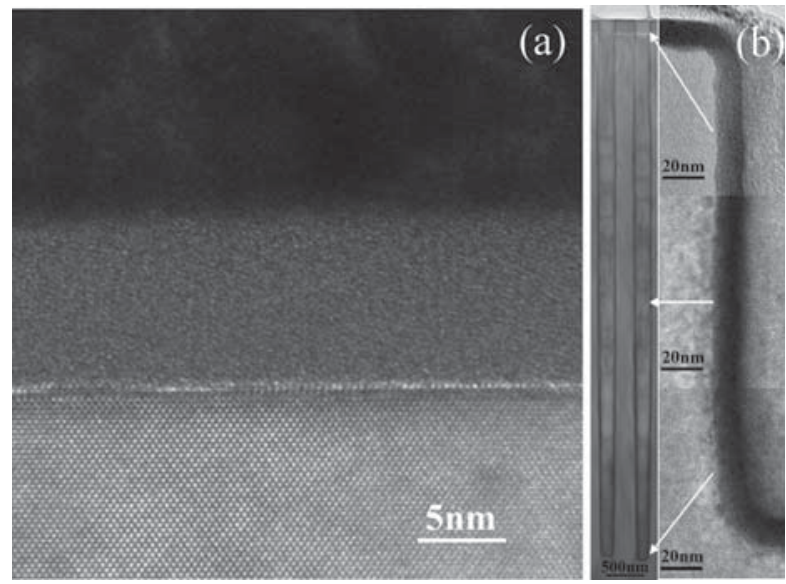

Figure 2. (a) XTEM image of a $\mathrm{WN} / \mathrm{LaScO}_{3}$ stack on $\mathrm{Si}$ substrate. The white line along the interface is caused by transmission electron microscope aberration. It consists of discrete spots, which are an extension of the $\mathrm{Si}$ lattice. (b) A $12 \mathrm{~nm} \mathrm{LaLuO}$ film deposited in holes with aspect ratio 80:1. The hole has an elliptical cross section with semi-long axes $75 \mathrm{~nm}$ and semi-short axes $35 \mathrm{~nm}$. Its depth is $7.2 \mu \mathrm{m}$. On the right-hand side are three higher magnification images for comparing the film thickness in the top, middle, and bottom parts of the trench.
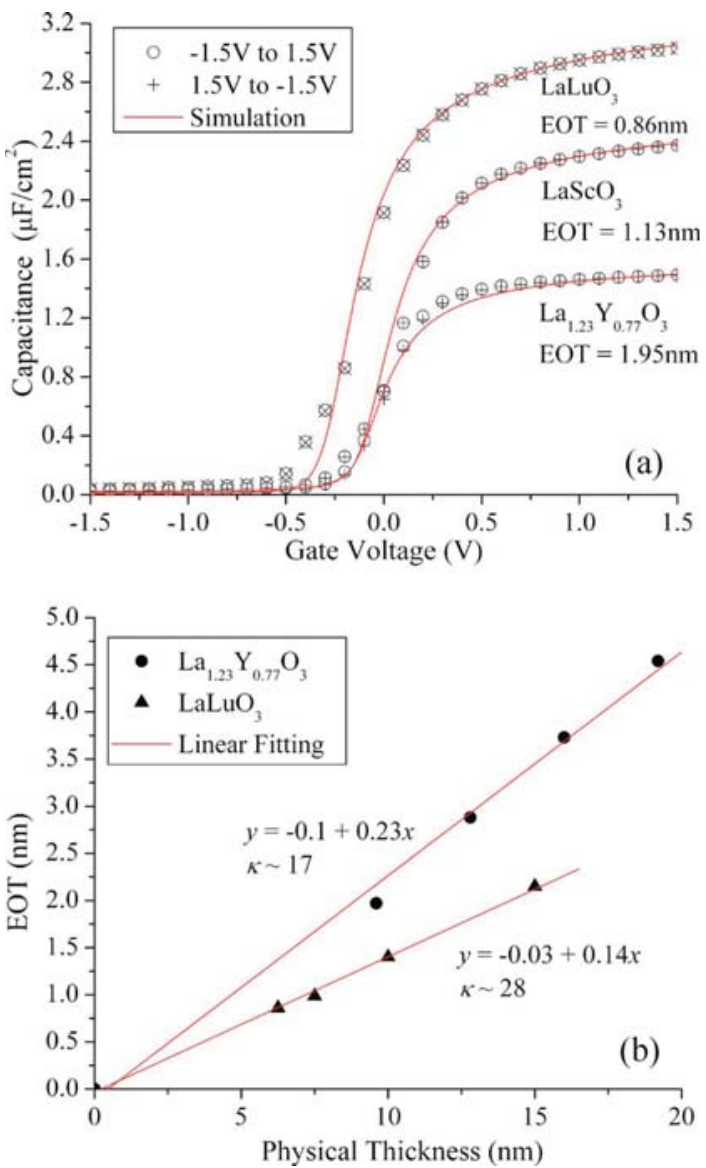

Figure 3. (Color online) (a) $C$ - $V$ curves measured at $1 \mathrm{MHz}$. The lines are simulated curves with MISFIT by assuming no interface traps. (b) The EOT plots as a function of the physical thickness.

noticeable stretching or shoulders. The small hysteresis $(0-10 \mathrm{mV})$ indicates very few bulk traps in the films. The 10 and $100 \mathrm{kHz} C-V$ curves (not shown) are closely aligned to $1 \mathrm{MHz}$ ones with frequency dispersion less than 2-3\% of the accumulation capacitance. Small shoulders appear in the weak inversion region of $C$ - $V$ curves measured at 10 and $100 \mathrm{kHz}$, which indicate the existence of some slowly responding interface states. The EOT was obtained by fitting the $C-V$ data to ideal simulation curves using the Metal-InsulationSemiconductor CV Fitting (MISFIT) program with charge quantization effect (Fig. 3a). ${ }^{9}$ By linearly fitting the EOT vs physical thickness plot in Fig. 3b, the dielectric constants, extracted from the slopes, are $28 \pm 1$ and $17 \pm 1.3$ for $\mathrm{LaLuO}_{3}$ and $\mathrm{La}_{1.23} \mathrm{Y}_{0.77} \mathrm{O}_{3}$ films, respectively. The nearly zero intercept for $\mathrm{LaLuO}_{3}$ films indicate the absence of any interfacial layer, consistent with the sharp interfaces observed by high-resolution XTEM. The dielectric constant for $\mathrm{LaScO}_{3}$ is $\sim 23$, which is estimated by $\kappa=3.9 t_{\text {physical }} /$ EOT. Both $\mathrm{LaScO}_{3}$ and $\mathrm{LaLuO}_{3}$ films have higher dielectric constants than those of their binary oxide components, i.e. $\mathrm{La}_{2} \mathrm{O}_{3}(\kappa \sim 19),{ }^{10} \mathrm{Lu}_{2} \mathrm{O}_{3}$ (16), and $\mathrm{Sc}_{2} \mathrm{O}_{3}$ (17). These results imply that the amorphous ternary oxides form new microscopic structures, rather than simple mixtures of the two binary oxides. In view of the continuous random network theory, ${ }^{11}$ it is possible that locally -O$\mathrm{La}-\mathrm{O}-\left(\mathrm{La}^{3+}\right.$ radius $\left.103 \mathrm{pm}\right)$ develops frames of polyhedrons with the smaller ions $\left(\mathrm{Sc}^{3+}\right.$ radius $75 \mathrm{pm}$ or $\left.\mathrm{Lu}^{3+} 86 \mathrm{pm}\right)$ caged inside. The $\mathrm{Sc}-\mathrm{O}$ or $\mathrm{Lu}-\mathrm{O}$ bonds are softened due to their smaller metal ion sizes, and the polarizability is therefore enhanced by the bond soft- 

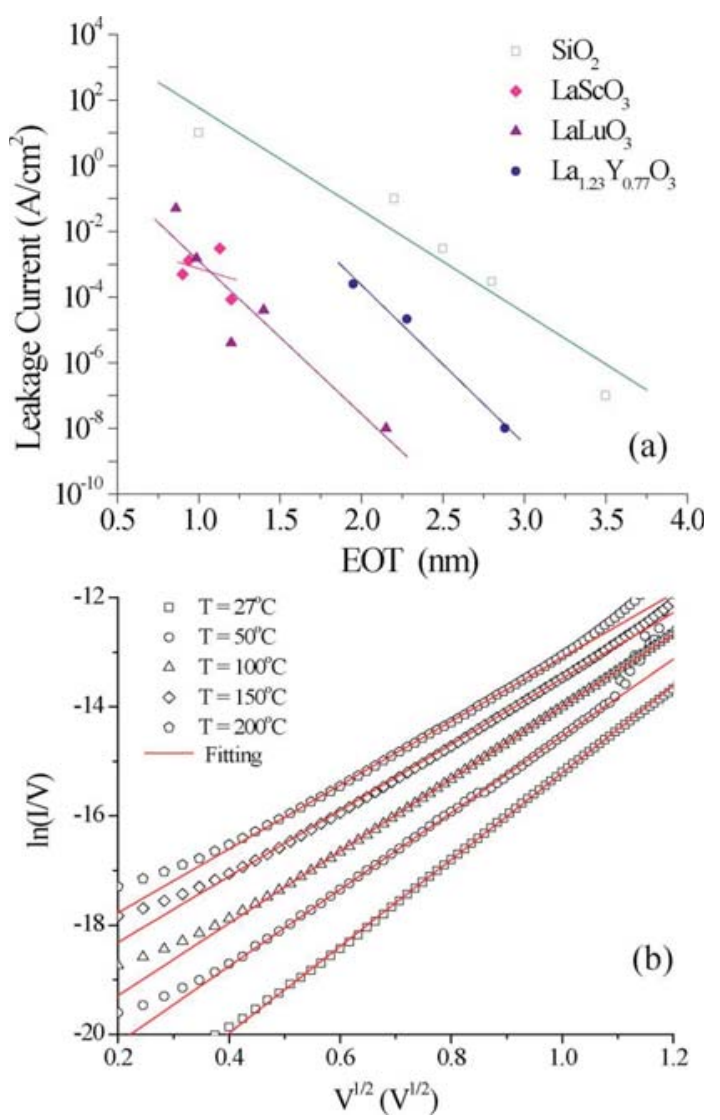

Figure 4. (Color online) (a) Leakage current density at $\left|V_{\mathrm{g}}-V_{\mathrm{FB}}\right|=1 \mathrm{~V}$ and (b) Poole-Frenkel plot of the leakage current density of a $\mathrm{LaScO}_{3}$ film $(\mathrm{EOT}=0.9 \mathrm{~nm})$ at various temperatures.

ening, which can be more than enough to make up for an adverse effect caused by the relatively larger molar volume in the amorphous films. ${ }^{12}$

Figure 4a shows the leakage current density scaling of our ALD films compared to that of thermal $\mathrm{SiO}_{2}$ films with the same EOT. The current density at $1 \mathrm{~V}$ gate bias $\left(\left|V_{\mathrm{g}}-V_{\mathrm{FB}}\right|=1 \mathrm{~V}\right)$ is up to 6 orders of magnitude lower than that of thermal $\mathrm{SiO}_{2}$ for both $\mathrm{LaScO}_{3}$ and $\mathrm{LaLuO}_{3}$ films and 2-4 orders of magnitude lower for $\mathrm{La}_{1.23} \mathrm{Y}_{0.77} \mathrm{O}_{3}$ films. All ternary oxide films have the same leakage current-voltage $(J-V)$ behaviors. Figure $4 \mathrm{~b}$ shows the $J$ - $V$ curves of a $\mathrm{LaScO}_{3}$ film with $0.9 \mathrm{~nm}$ EOT at temperatures from room temperature to $200^{\circ} \mathrm{C}$. The Poole-Frenkel plots (Fig. 3b) of this $J$-V measurement show linear behaviors in the range of $0.3-1.5 \mathrm{~V}$. The dynamic refraction index calculated from the slopes is $\sim 1.9$ to 2.0, which is comparable to the optical refraction index measured at wavelength of $630 \mathrm{~nm}$. The leakage currents also obey the Arrhenius law at different fixed voltages (not shown). Combining these two observations, we conclude that $J=c V \exp \left\{-\left[\left(\phi_{\mathrm{B}}-\beta_{\mathrm{PF}} V^{1 / 2}\right) / k_{\mathrm{B}} T\right]\right\}$, which is exactly the PooleFrenkel formula. The extracted trap depth $\phi_{\mathrm{B}}$ is $0.3-0.4 \mathrm{eV}$.

\section{Conclusions}

In summary, $\mathrm{La}_{x} \mathrm{M}_{2-x} \mathrm{O}_{3}(\mathrm{M}=\mathrm{Sc}$, Lu, or $\mathrm{Y})$ films were deposited by ALD with metal amidinate precursors and $\mathrm{H}_{2} \mathrm{O}$. Both $\mathrm{LaScO}_{3}$ and $\mathrm{LaLuO}_{3}$ films are amorphous and free of interfacial layers. Besides the structural benefits, both oxides have high dielectric constants $\left(\sim 23\right.$ for $\mathrm{LaScO}_{3}$ and $28 \pm 1$ for $\left.\mathrm{LaLuO}_{3}\right)$, low leakage current density, and very few bulk traps, and are scalable to EOT $<1 \mathrm{~nm}$. $\mathrm{La}_{1.23} \mathrm{Y}_{0.77} \mathrm{O}_{3}$ films have polycrystalline structures with moderately high $\kappa=17 \pm 1.3$ and low leakage current. The PooleFrenkel mechanism is verified in the ternary oxide films by studying temperature dependence of the leakage current.

\section{Acknowledgments}

This work was supported in part by Rohm and Haas Electronic Materials and performed, in part, at Harvard University's Center for Nanoscale Systems, a member of the National Nanotechnology Infrastructure Network, supported by the U.S. National Science Foundation under award no. ECS-0335765. We also thank Professor Ramanathan for helping in the leakage current measurement. ticle.

Harvard University assisted in meeting the publication costs of this ar-

\section{References}

1. http://www.intel.com/technology/architecture-silicon/45nm-core2/

2. H. Kim, P. C. McIntyre, and K. C. Saraswat, Appl. Phys. Lett., 82, 106 (2003).

3. J. Robertson, Mater. Res. Bull., 27, 217 (2002).

4. J. M. J. Lopes, U. Littmark, M. Roeckerath, St. Lenk, J. Schubert, and S. Mantl, J. Appl. Phys., 101, 104109 (2007); J. M. J. Lopes, M. Roeckerath, T. Heeg, U. Littmark, J. Schubert, S. Mantl, Y. Jia, and D. G. Schlom, Microelectron. Eng., 84, 1890 (2007).

5. J. M. J. Lopes, M. Roeckerath, T. Heeg, E. Rije, J. Schubert, S. Mantl, V. V. Afanas'ev, S. Shamuilia, A. Stesmans, Y. Jia, et al., Appl. Phys. Lett., 89, 222902 (2006).

6. J. H. J. Lopes, M. Roeckerath, T. Heeg, J. Schubert, U. Litmark, S. Mantl, A Besmehn, P. Myllymaki, L. Niinisto, C. Adamo, et al., ECS Trans., 11(4), 311 (2007)

7. K. H. Kim, D. B. Farmer, J.-S. M. Lehn, P. V. Rao, and R. G. Gordon, Appl. Phys Lett., 89, 133512 (2006)

8. J. S. Becker, S. Suh, S. Wang, and R. G. Gordon, Chem. Mater, 15, 2969 (2003)

9. G. Apostolopoulos, G. Vellianitis, A. Dimoulas, J. C. Hooker, and T. Conrad, Appl. Phys. Lett., 84, 260 (2004).

10. H. Yamada, T. Shimizu, A. Kurokawa, K. Ishii, and E. Suzuki, J. Electrochem Soc., 150, G429 (2003); S. Y. No, D. Eom, C. S. Hwang, and H. J. Kim, J. Appl. Phys. 100, 024111 (2006); W. M. He, S. Schuetz, R. Solanki, J. Belot, and J. McAndrew, Electrochem. Solid-State Lett., 7, G131 (2004).

11. R. Zallen, The Physics of Amorphous Solids, Wiley-VCH, Hoboken, NJ (1998)

12. E. Cockayne, J. Appl. Phys., 103, 084103 (2008). 